\title{
An approach for choosing the optimal route and type of transport for freight carriage using Compromise programming
}

\author{
Svetla Stoilova ${ }^{1, *}$ \\ Technical University - Sofia, Faculty of Transport, 8 Kliment Ohridski Blvd., 1000 Sofia, Bulgaria
}

\begin{abstract}
This study elaborates a methodology for choosing a transport strategy based on the selection of the optimal route and type of transport. The research examines carriage by containers and includes two ways of transportation: by container block trains and by trucks. The methodology consists of three steps. The first step defines the determination of alternatives routes and criteria for assessment. Eight criteria have been studied: environmental protection; economic criteria; additional transportation fare; the duration of transportation; transhipment operations; security; reliability; stability. In the second step three approaches have been used and compared to determine the weights of the criteria: the Shannon entropy method, which is based on information from data, expert assessments by means of the Analytic hierarchy process (AHP) method and the Decision Making Trial and Evaluation Laboratory (DEMATEL) method. The third step determines the optimal solution based on the Compromise programming method. The methodology is approbated for routes from the railway and road network of Bulgaria. The results show that the criteria with the greatest impact are: the economic criteria; the duration of transportation and environmental protection. It was found out that the technologies that include rail transport are the best variant of transportation. The presented methodology could be used for choosing transportation for other destinations in the transport network.
\end{abstract}

\section{Introduction}

Different factors influence the choice of route and type of transport. For transport companies it is important that carriage is carried out with minimal transport costs. For transport users it is important to carry out the transport operations with the minimum delivery time, and minimum reloading operations. Considering the policy of the European Union, transport should be carried out with minimal environmental pollution. It can be summed up that, apart from the operating costs which are of major importance for selecting a route and the type of transportation, additional criteria such as environmental, technological and other ones also have impact.

Different authors have studied the factors of transportation. As key indicators in transport have been established the following factors: transport cost, transport time, flexibility, reliability, quality and sustainability, $[1,2]$. In [3] the environmental aspects of transport have been considered. In [4] has been studied the problems for establishment of freight intermodal terminals. In [5] a model has been developed to optimize the collection and delivery of parcels on routes in an urban environment. The methods of multi-criteria analysis have been applied to assess the weights of the criteria and to choose the best alternatives. Some of methods use priority (AHP method), outranking techniques (PROMETHEE method), distance function and mathematical programming (Compromise programming), or mixed solutions. The multi-criteria decision making approach Analytic Hierarchy Process (AHP) is applied in many studies. In [6] it has been applied for best routes prioritization and selection. The authors examine criteria costs, time, risk of freight damaged, risk of infrastructure and equipment, risk of other factors for multimodal routes selection and they elaborate a decision support system using AHP Method and Zero-One Goal Programming. In [7] the AHP method is used to choose the best alternative route. The criteria: risk of explosion or spill, risk of road accidents, consequences of an incident, travel time and travel cost have been considered. By using the AHP method in $[8,9]$ are examined the factors: distance, terrain, road condition, convenience, safety and accessibility in the route selection. In [10] four groups of main criteria environmental, economic, technological and social have been determined to assess the transportation with intermodal transport. The Decision Making Trial and Evaluation Laboratory (DEMATEL) multi-criteria method was used two determine the weights of the criteria and also to study the mutual influences of the criteria. It has been used in transport to evaluate criteria for tourism marketing [11]; in supply chain management [12]. In [13] a three-phase model for selection of the route of a road train has been presented. The criteria that have been studied are criteria of the road, criteria related to the throughput of the road, criteria related to the convenience of travel. The PROMETHEE method has been used to evaluate the alternatives of route selection in [14].

\footnotetext{
*Corresponding author: stoilova@tu-sofia.bg
} 
Study [15] elaborates a methodology for determining optimal routes for dangerous goods transportation by means of the compromise programming approach. The case study is carried out for the transportation on the road network of Hong Kong. The studied criteria are travel time, probability of an incident, road users at risk, off-road population at risk, people with special needs at risk, negative impact on the economy: industrial, commercial and transport facilities at risk. The Compromise programming method has been applied also for research in air transport management [16], in water transportation [17] for economic research [18], to assess ecosystems [19]. This method is suitable for application when the criteria have a different type of optimization.

It can be said that the methods of multi-criteria analysis are appropriate for choosing the best alternative of transportation.

This paper aims to propose an approach for selecting a route and type of transportation for carriage of containers between two points by taking into account multiple factors relevant for transport and by using the Compromise programming method. This proposal is motivated by the fact that Compromise programming is a mathematical decision support model to obtain scores of alternatives by minimizing the weighted distances to an ideal point.

\section{Methodology}

The methodology for selection of a route and the type of transportation includes the following steps, Fig.1.

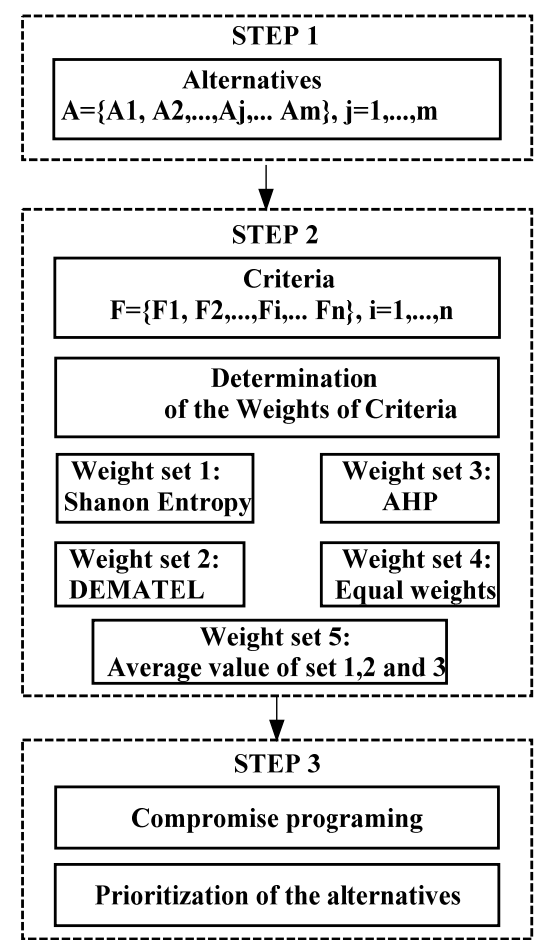

Fig. 1. Scheme of the methodology.

Step 1: Selection of alternatives variants of transportation. The carriage options including rail and road transport are examined in this research. The set of alternatives is: $A=\{A 1, A 2, \ldots, A j, \ldots, A m\}$.
Step 2: Definition of quantitative and qualitative criteria for the assessment of alternatives routes for railway and road transport of containers. The set of criteria is: $F=\{F 1, F 2, \ldots, F i, \ldots, A n\}$.

The following criteria are studied in the research:

- F1: Carbon dioxide emissions, g;

- F2: Economic Criteria. This includes transport costs and infrastructure charges, BGN;

- F3: Presence of additional transportation fare, coeff.;

- F4: The duration of transportation, h;

- F5: Presence of transhipment operations, coeff.;

- F6: Security, coeff.;

- F7: Reliability, coeff.;

- F8: Stability, coeff.

Criteria F1, F2 and F4 are quantitative and values need to be set for them. Criteria F3, F5, F6 and F7 are qualitative. They have to be set with " 1 " and " 0 ". The value is " 1 " if the answer is "yes", and " 0 ", otherwise.

The study proposes five sets to define the criteria weights:

- Set 1: Shannon Entropy method

$$
W_{E}=\left\{w_{E 1}, w_{E 2}, \ldots, w_{E i}, \ldots, w_{E n}\right\}
$$

where $w_{E i}$ are the weights determined by using Shannon entropy method;

- Set 2: DEMATEL Method

$$
W_{D}=\left\{w_{D 1}, w_{D 2}, \ldots, w_{D i}, \ldots, w_{D n}\right\},
$$

where $w_{D i}$ are the weights determined by using DEMATEL method;

- Set 3: AHP Method

$$
W_{A H P}=\left\{w_{A H P 1}, w_{A H P 2}, \ldots, w_{A H P i}, \ldots, w_{A H P n}\right\},
$$

where $w_{A H P i}$ are the weights determined by using AHP method;

- Set 4: Equal weights:

$$
W_{E Q}=\left\{w_{E Q 1}, w_{E Q 2}, \ldots, w_{E Q i}, \ldots, w_{E Q n}\right\} .
$$

The values of equal weights are determined as:

$$
w_{E Q 1}=w_{E Q 2}=\cdots=w_{E Q i}=\cdots=w_{E Q n}=\frac{1}{n} .
$$

- Set 5: Average values by set 1,2 and 3:

$$
W_{A V}=\left\{w_{A V 1}, w_{A V 2}, \ldots, w_{A V i}, \ldots, w_{A V n}\right\} .
$$
follow:

The average value of each weight is determined as

$$
w_{A V, i}=\frac{w_{E, i}+w_{D, i}+w_{A H P, i}}{3} .
$$

The Shannon Entropy method allows us to determine the weights of criteria based of the information of the data, [20-22]. In this case the received results are not subjective. Both multi-criteria methods AHP and DEMATEL use expert's assessment to evaluate the criteria. AHP method applies Saaty's scale for pairwise comparison of criteria, the DEMATEL method uses another scale to assess the influence between criteria. The determined weights are dependent on the opinion of the 
experts. The case with equal weights permits us to investigate the changes in rating the alternatives. This approach is identical with the case where the weights of criteria are not taken into account. The average value of the weights given by the Shannon entropy method, DEMTEL method and AHP method permits to reduce subjectivism when making a decision.

The application of these sets of weights assessment makes it possible to do a sensitivity analysis of the results.

Step 3: Ranking the alternative variants of the transportation by using Compromise programming. Choice of optimal variant of transportation.

Compromise programming is a distance method of multi-criteria analysis based on mathematical programming. This method is appropriate when it is necessary to decide on contradictory criteria (minimum and maximum optimization).

\subsection{Determining the weights of the criteria using Shannon entropy}

The information entropy for each criterion $F_{j}$ is determined as follows, [20-22]:

$$
\begin{gathered}
E_{j}=-k \sum_{i=1}^{n} p_{i j} \ln p_{i j} ; \\
k=1 / \ln n \\
0 \leq E_{j} \leq 1,
\end{gathered}
$$

where: $k$ is a constant; $p_{i j}$ - the normalized values of decision matrix $\left(x_{i j}\right)_{m x n}, i=1, \ldots, n$ - number of criteria, $j=1, \ldots m$ - the number of alternatives.

The decision matrix $\left(x_{i j}\right)_{m x n}$ is formed according to the data of the criteria for the studied alternatives.

The normalized values are determined as follows:

$$
p_{i j}=\frac{x_{i j}}{\sum_{i=1}^{n} x_{i j}}
$$

To determine the weights of the criteria it is necessary to calculate parameter $d_{j}$ for each alternative as follows:

$$
d_{j}=1-E_{j}
$$

The weights of the criteria are determined as follows:

$$
\begin{gathered}
w_{j}=\frac{d_{j}}{\sum_{j=1}^{m} d_{j}} ; \\
0 \leq w_{j} \leq 1 \\
\sum_{j=1}^{m} w_{j}=1 .
\end{gathered}
$$

\subsection{Determining the weights of the criteria through the AHP Method}

The AHP method is a multi-criteria decision approach. It is based on a pairwise comparison between criteria using a standardized comparison scale of nine levels named Saaty's scale. The comparison scale is shown in Table 1, [23].
Table 1. Saaty's scale for AHP score.

\begin{tabular}{|l|c|}
\hline \multicolumn{1}{|c|}{ Importance } & Score \\
\hline Equal & 1 \\
\hline Moderate & 3 \\
\hline Strong or essential & 5 \\
\hline Very strong & 7 \\
\hline Extreme & 9 \\
\hline Values for intermediate comparison & $2,4,6,8$ \\
\hline
\end{tabular}

By using the AHP method is formed the $A(\mathrm{n}, \mathrm{n})$ evaluation square matrix based on the pairwise comparison on $n$ criteria using Saaty's scale. For the matrix elements are used the following dependencies:

$$
a_{i i}=1 ; a_{i j} \neq 0 ; a_{j i} \neq 0 ; a_{j i}=1 / a_{i j} .
$$

To determine the weights of the criteria it is necessary to normalize the evaluation matrix.

The weights of the criteria are determined according to the following equation:

$$
A W=\lambda_{\max } W
$$

where $W=\left\{w_{1}, \ldots, w_{n}\right\}^{T}$ is the normalized right eigenvector; $\lambda_{\max }-$ the largest eigenvalue of the evaluation square matrix $A$ :

$$
\lambda_{\max }=\sum_{i=1}^{n}\left[\left(\sum_{j=1}^{n} a_{i j}\right) \cdot w_{i}\right] .
$$

With the AHP method the results are mathematically validated using the consistency ratio $C R$.

$$
C R=C I / R I \leq 0,1,
$$

where: $C I$ is the consistency index; $R I-$ a random index. The random matrix is given by [20].

The consistency index is:

$$
C I=\frac{\lambda_{\max }-n}{n-1} .
$$

If the condition (19) is met, the results are considered to be satisfactory. If the condition (19) is not met, it is necessary to make some revisions of scores.

\subsection{Determining the weights of criteria by using DEMATEL Method}

The DEMATEL method is a multi-criteria decision approach which determines the weights of the criteria and also the mutual influences of the criteria.

The procedure of the DEMATEL method includes the following, [24]: determination of the perception matrix; calculation of the average normalized perception matrix and the total relation matrix; determination of the normalized degree of influence of each criterion; calculation of the threshold value to obtain a cause and effect relationship diagram.

The scale of evaluation of criteria consists of the following scores: 0 - no influence; 1 - low influence; 2 medium influence; 3 - high influence; 4 - very high influence. This scale is used by each of the experts who evaluate the direct influence between any two factors and thus a perception matrix is created. The diagonal elements 
of the perception matrix for $i=j$, are set to zero. When the scores of each expert are obtained, the average perception matrix $A$ is formed as the average values of experts' assessments.

The average normalized perception matrix $D_{n x n}$ is calculated as:

$$
D=A / S,
$$

where $A$ is the average perception matrix; $S$ - the major value of the sum of each column $j$ of the matrix $A$ and the sum of each row $i$ of the matrix $A$.

The values of each element in matrix $D$ are between zero and one.

The total relation matrix $T_{n x n}$ is determined with this method as follows:

$$
T=D(I-D)^{-1}
$$

where $I$ is an $n x n$ identity matrix.

For each criterion the normalized degree of influence is determined as follows:

$$
e_{i}=\frac{r_{i}+c_{i}}{\sum_{i=1}^{n}\left(r_{i}+c_{i}\right)} 100, \%
$$

where $r_{i}, c_{i}$ are the elements of vector $R$ and vector $C$.

The degree of influence corresponds to the weights of the criteria.

Vector $C$ represents the sum of the columns of the $T$ matrix:

$$
\begin{gathered}
R=\left[r_{i}\right]_{n x 1}=\left[\sum_{j=1}^{n} t_{i j}\right]_{n x 1} ; \\
C=\left[c_{j}\right]_{1 x n}^{\prime}=\left[\sum_{i=1}^{n} t_{i j}\right]_{1 x n},
\end{gathered}
$$

where $r_{i}$ is the sum of the $i$-th row in matrix $T ; c_{j}$ - the sum of the $j$-th column in matrix $T ;{ }^{\prime}-$ symbol meaning the transposed matrix.

The elements of vector $R$ present both the direct and indirect effects by the $i$-th criterion on the other criteria. The elements of vector $C$ show both direct and indirect effects by criterion $j$ from the other.

With the DEMATEL method we determine a threshold value that serves to determine the relationships between the criteria in the considered system. The threshold value $v$ is determined as an average value of the elements of matrix $T,[25]$ :

$$
v=\frac{\sum_{i=1}^{n} \sum_{j=1}^{n}\left[t_{i j}\right]}{N}
$$

where $N$ is the total number of elements in matrix $T$.

After determining the values of the threshold value all elements of matrix $T$ are compared with its value. The elements that are smaller or are equal to the threshold value $v$, are set to zero. The elements that are larger than the threshold value $v$, retain their value.

\subsection{Ranking the alternative variants of trans- porttation by using Compromise programming}

In this research prioritization of the alternatives is made using the Compromise programming (CP) method. This method defines the best/suitable solution as the one set of efficient solutions whose point is at the smallest distance from an ideal point. The objective is to obtain a solution that is as close as possible to some ideal solution. The criterion of optimization is, [19]:

$$
\begin{aligned}
\operatorname{minL}_{p}= & {\left[\sum_{j=1}^{m} w_{j}^{p} \cdot\left|\frac{x_{j}^{*}-x_{j}}{M_{j}-m_{j}}\right|^{p}\right]^{1 / p} ; } \\
& \sum_{j=1}^{m} w_{j}=1 ; \\
& w_{j} \in\{0,1\} ; \\
& 1 \leq p<\infty,
\end{aligned}
$$

where $L_{p}$ is a metric for alternative; $x_{j}$ - value of criterion $j$ for alternative $A ; M_{j}$ - the maximum value of criterion $j$ in set $N ; m_{j}$ - the minimum value of criterion $j$ in set $N$; $x_{j}^{*}$ - ideal value of criterion $j ; w_{j}$ is the weight of the criterion $j ; p$ - parameter. The parameter $p$ name also balancing factor and use to present the attitude of the decision-maker to the optimal solution.

The values of parameter $p$ give a different measure of the distance from an efficient point to the reference point. The calculation with different values of parameter $p$ permits us to have a perfect compensation among the objectives. When $p=1$ is the so-called street-block distance, or Manhattan distance. The Manhattan distance between two points presents a grid found on a strictly horizontal and/or vertical path. When $p=2$, it represents the Euclidean distance. The Euclidean distance is a diagonal of the horizontal and vertical components. When $p=\infty$, it is Tchebyshev distance, and corresponds to minmax problem.

The most popular value of solving Compromise programming is $p=2$, as it is the shortest distance.

The optimal alternative is the one with lowest value for the $L_{p}$ metric. By this method this will be the best compromise solution because it is the solution nearest to the ideal point.

\section{Results end discussion}

\subsection{Definition of the alternatives and criteria}

The methodology is approved for container transport by rail and road for direction Sofia - Varna in Bulgaria. Figures 2 and 3 show maps of the alternatives in railway and road network.

This research studied the alternatives given in [14]:

- A1: Freight block train: Iliyantsi-Gorna OryahovitsaVarna;

- A2: Freight block train: Iliantsi-Karlovo-KarnobatVarna;

- A3: Road train: Route Sofia-Veliko Tarnovo-Varna;

- A4: Road train: Route Sofia-Plovdiv-Burgas-Varna;

- A5: Road train: Route Sofia-Plovdiv-KarnobatShumen-Varna. 


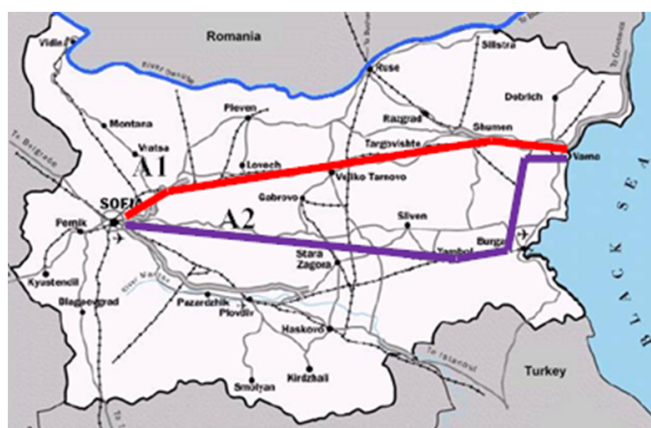

Fig. 2. Scheme of the alternatives - railway transport.

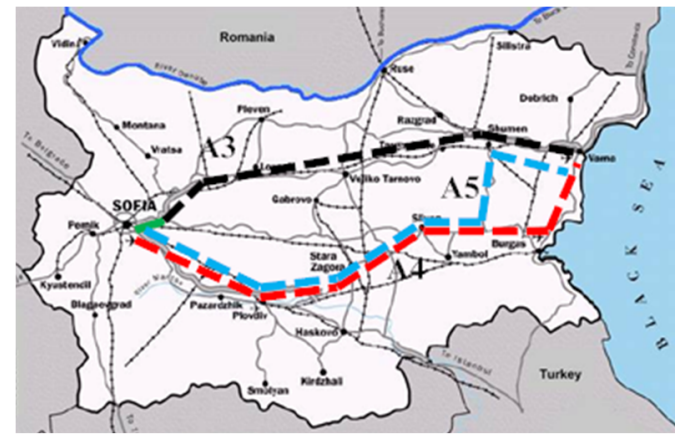

Fig. 3. Scheme of the alternatives - road transport.

The values of the quantitative criteria have to be determined for each alternative. This applies to the criteria of carbon dioxide emissions (F1), economical criteria (F2), travel time (F3). The qualitative criteria have to be set with " 1 " and " 0 ". The value is " 1 " if the answer is "yes", and "0", otherwise.

Table 2 gives the values of the criteria. In order to compare the results, the criteria are set for one road train. The last row of Table 2 gives the type of optimization (minimum or maximum). The values of the carbon dioxide emissions, economic criteria and the duration of transportation are as in [14].

Table 2. Criteria values of Decision matrix.

\begin{tabular}{|c|c|c|c|c|c|c|c|c|}
\hline$F_{i}$ & $\mathrm{~F} 1$ & $\mathrm{~F} 2$ & $\mathrm{~F} 3$ & $\mathrm{~F} 4$ & $\mathrm{~F} 5$ & $\mathrm{~F} 6$ & $\mathrm{~F} 7$ & $\mathrm{~F} 8$ \\
\hline$A_{j}$ & $\mathrm{Co} 2, \mathrm{~g} / \mathrm{RT}$ & $\mathrm{BGN} / \mathrm{RT}$ & - & $\mathrm{h}$ & - & - & - & - \\
\hline A1 & 238257 & 431 & 1 & 9,05 & 1 & 1 & 1 & 1 \\
\hline A2 & 247250 & 413 & 1 & 8,57 & 1 & 1 & 1 & 1 \\
\hline A3 & 442887 & 469 & 0 & 7,14 & 0 & 0 & 0 & 0 \\
\hline A4 & 519180 & 544 & 0 & 8,12 & 0 & 0 & 0 & 0 \\
\hline A5 & 545931 & 468 & 0 & 8,62 & 0 & 0 & 0 & 0 \\
\hline type & min & min & min & min & min & max & $\max$ & max \\
\hline
\end{tabular}

\subsection{Determining the weights of the criteria}

Table 3 and Table 4 show the normalized decision matrix and results of the Shannon Entropy method.

Table 3. Normalized values $p_{i j}$ of decision matrix.

\begin{tabular}{|c|c|c|c|c|c|c|c|c|}
\hline$A_{j}$ & $\mathrm{~F} 1$ & $\mathrm{~F} 2$ & $\mathrm{~F} 3$ & $\mathrm{~F} 4$ & $\mathrm{~F} 5$ & $\mathrm{~F} 6$ & $\mathrm{~F} 7$ & $\mathrm{~F} 8$ \\
\hline A1 & 0,12 & 0,25 & 0,50 & 0,22 & 0,50 & 0,50 & 0,50 & 0,50 \\
\hline A2 & 0,12 & 0,24 & 0,50 & 0,21 & 0,50 & 0,50 & 0,50 & 0,50 \\
\hline A3 & 0,22 & 0,24 & 0,00 & 0,17 & 0,00 & 0,00 & 0,00 & 0,00 \\
\hline A4 & 0,26 & 0,28 & 0,00 & 0,20 & 0,00 & 0,00 & 0,00 & 0,00 \\
\hline A5 & 0,27 & 0,24 & 0,00 & 0,21 & 0,00 & 0,00 & 0,00 & 0,00 \\
\hline
\end{tabular}

Table 4. Parameters of Shannon entropy method.

\begin{tabular}{|c|c|c|c|c|c|c|c|c|}
\hline$F i$ & $\mathrm{~F} 1$ & $\mathrm{~F} 2$ & $\mathrm{~F} 3$ & $\mathrm{~F} 4$ & $\mathrm{~F} 5$ & $\mathrm{~F} 6$ & $\mathrm{~F} 7$ & $\mathrm{~F} 8$ \\
\hline$E_{j}$ & 0,32 & 0,43 & 0,69 & 0,30 & 0,69 & 0,69 & 0,69 & 0,69 \\
\hline$d_{j}$ & 0,68 & 0,57 & 0,31 & 0,70 & 0,31 & 0,31 & 0,31 & 0,31 \\
\hline$w_{j}$ & 0,20 & 0,16 & 0,09 & 0,20 & 0,09 & 0,09 & 0,09 & 0,09 \\
\hline
\end{tabular}

The scores of the AHP method are presented in Table 5. In the study the assessments have been made by five experts who gave a general assessment. The last column of the table shows the weights of the criteria using the AHP method. In the last row of the table is the value of the consistency ratio. It can be seen that according to formula (19) the experts' assessments are satisfactory, $(\mathrm{CR}=0,06 ; \mathrm{CR}<0,1)$.

Table 5. Prioritization Matrix resulting from using the AHP method.

\begin{tabular}{|c|c|c|c|c|c|c|c|c|c|}
\hline$F_{i}$ & $\mathrm{~F} 1$ & $\mathrm{~F} 2$ & $\mathrm{~F} 3$ & $\mathrm{~F} 4$ & $\mathrm{~F} 5$ & $\mathrm{~F} 6$ & $\mathrm{~F} 7$ & $\mathrm{~F} 8$ & $w_{j}$ \\
\hline F1 & 1 & $1 / 3$ & 3 & 1 & 1 & 1 & 1 & 1 & 0,10 \\
\hline F2 & 3 & 1 & 5 & 5 & 5 & 2 & 2 & 2 & 0,32 \\
\hline F3 & $1 / 3$ & $1 / 5$ & 1 & 1 & 4 & 1 & 1 & 1 & 0,11 \\
\hline F4 & 1 & $1 / 5$ & 1 & 1 & 5 & 1 & 2 & 2 & 0,14 \\
\hline F5 & 1 & $1 / 5$ & $1 / 4$ & $1 / 5$ & 1 & 1 & 1 & 1 & 0,06 \\
\hline F6 & 1 & $1 / 2$ & 1 & 1 & 1 & 1 & 2 & 1 & 0,11 \\
\hline F7 & 1 & $1 / 2$ & 1 & $1 / 2$ & 1 & $1 / 2$ & 1 & 1 & 0,08 \\
\hline F8 & 1 & $1 / 2$ & 1 & $1 / 2$ & 1 & 1 & 1 & 1 & 0,08 \\
\hline \multicolumn{9}{|c|}{ CR $=0,06$} \\
\hline
\end{tabular}

Table 6 presents the average matrix of the experts' scores resulting from using the DEMATEL method. In the study the assessments have been given by five experts. They are given independently of each other. Table 7 and Table 8 show the average normalized matrix and total relation matrix.

Table 6. Average matrix resulting from using the DEMATEL method.

\begin{tabular}{|c|c|c|c|c|c|c|c|c|}
\hline Fi & F1 & F2 & F3 & F4 & F5 & F6 & F7 & F8 \\
\hline F1 & 0,00 & 1,96 & 0,00 & 0,09 & 0,00 & 0,43 & 0,00 & 0,00 \\
\hline F2 & 3,96 & 0,00 & 3,96 & 3,96 & 0,04 & 1,96 & 0,04 & 0,43 \\
\hline F3 & 0,04 & 2,87 & 0,00 & 0,43 & 0,04 & 0,04 & 0,04 & 0,04 \\
\hline F4 & 0,61 & 1,96 & 1,04 & 0,00 & 0,04 & 0,43 & 1,48 & 0,43 \\
\hline F5 & 0,00 & 0,61 & 0,87 & 2,04 & 0,00 & 0,00 & 0,43 & 0,00 \\
\hline F6 & 0,00 & 1,87 & 0,13 & 0,74 & 0,61 & 0,00 & 0,43 & 0,43 \\
\hline F7 & 0,04 & 1,48 & 0,04 & 0,87 & 0,74 & 0,04 & 0,00 & 0,26 \\
\hline F8 & 0,26 & 1,04 & 0,61 & 0,00 & 0,00 & 1,13 & 0,26 & 0,00 \\
\hline
\end{tabular}

Table 7. The average normalized matrix.

\begin{tabular}{|c|c|c|c|c|c|c|c|c|}
\hline$F_{i}$ & F1 & F2 & F3 & F4 & F5 & F6 & F7 & F8 \\
\hline F1 & 0,000 & 0,136 & 0,000 & 0,006 & 0,000 & 0,030 & 0,000 & 0,000 \\
\hline F2 & 0,276 & 0,000 & 0,276 & 0,276 & 0,003 & 0,136 & 0,003 & 0,030 \\
\hline F3 & 0,003 & 0,200 & 0,000 & 0,030 & 0,003 & 0,003 & 0,003 & 0,003 \\
\hline F4 & 0,042 & 0,136 & 0,073 & 0,000 & 0,003 & 0,030 & 0,103 & 0,030 \\
\hline F5 & 0,000 & 0,042 & 0,061 & 0,142 & 0,000 & 0,000 & 0,030 & 0,000 \\
\hline F6 & 0,000 & 0,130 & 0,009 & 0,052 & 0,042 & 0,000 & 0,030 & 0,030 \\
\hline F7 & 0,003 & 0,103 & 0,003 & 0,061 & 0,052 & 0,003 & 0,000 & 0,018 \\
\hline F8 & 0,018 & 0,073 & 0,042 & 0,000 & 0,000 & 0,079 & 0,018 & 0,000 \\
\hline
\end{tabular}

Table 8 presents the relation matrix. The number of elements of relation matrix is 64 . The value of threshold value is determined by formula (26). 
Table 8. Total relation matrix.

\begin{tabular}{|c|c|c|c|c|c|c|c|c|}
\hline$F_{i}$ & F1 & F2 & F3 & F4 & F5 & F6 & F7 & F8 \\
\hline F1 & 0,050 & 0,171 & 0,053 & 0,059 & 0,004 & 0,058 & 0,009 & 0,009 \\
\hline F2 & $\mathbf{0 , 3 5 0}$ & $\mathbf{0 , 2 0 4}$ & $\mathbf{0 , 3 6 4}$ & $\mathbf{0 , 3 6 1}$ & 0,016 & $\mathbf{0 , 1 9 1}$ & 0,049 & 0,055 \\
\hline F3 & 0,077 & $\mathbf{0 , 2 5 0}$ & 0,078 & $\mathbf{0 , 1 0 6}$ & 0,007 & 0,044 & 0,017 & 0,016 \\
\hline F4 & $\mathbf{0 , 1 0 6}$ & $\mathbf{0 , 2 1 4}$ & $\mathbf{0 , 1 4 1}$ & 0,076 & 0,013 & 0,069 & $\mathbf{0 , 1 1 5}$ & 0,044 \\
\hline F5 & 0,036 & $\mathbf{0 , 1 0 1}$ & $\mathbf{0 , 1 0 3}$ & $\mathbf{0 , 1 7 8}$ & 0,005 & 0,022 & 0,050 & 0,010 \\
\hline F6 & 0,056 & $\mathbf{0 , 1 8 3}$ & 0,073 & $\mathbf{0 , 1 1 6}$ & 0,047 & 0,034 & 0,046 & 0,041 \\
\hline F7 & 0,049 & $\mathbf{0 , 1 4 6}$ & 0,056 & $\mathbf{0 , 1 1 3}$ & 0,055 & 0,030 & 0,015 & 0,027 \\
\hline F8 & 0,053 & $\mathbf{0 , 1 1 8}$ & 0,080 & 0,043 & 0,006 & 0,099 & 0,026 & 0,009 \\
\hline
\end{tabular}

The values that are equal or greater than the threshold value $(v=0,084)$ are given in bold. This parameter serves to determine the relationships in the considered system.

Table 9 shows the direct and indirect influence of criteria. The last column presents the weights of the criteria.

Table 9. Direct and indirect impact of the criteria.

\begin{tabular}{|c|c|c|c|c|c|}
\hline Criterion & P & R & P+R & P-R & e\% \\
\hline F1 & 0,412 & 0,777 & 1,190 & $-0,365$ & $11 \%$ \\
\hline F2 & 1,590 & 1,387 & 2,977 & 0,202 & $28 \%$ \\
\hline F3 & 0,594 & 0,947 & 1,541 & $-0,353$ & $14 \%$ \\
\hline F4 & 0,779 & 1,053 & 1,831 & $-0,274$ & $17 \%$ \\
\hline F5 & 0,505 & 0,153 & 0,658 & 0,352 & $6 \%$ \\
\hline F6 & 0,596 & 0,546 & 1,142 & 0,049 & $10 \%$ \\
\hline F7 & 0,492 & 0,328 & 0,820 & 0,164 & $8 \%$ \\
\hline F8 & 0,434 & 0,210 & 0,644 & 0,224 & $6 \%$ \\
\hline
\end{tabular}

The prioritization is: $\mathrm{F} 2>\mathrm{F} 4>\mathrm{F} 3>\mathrm{F} 1>\mathrm{F} 6>\mathrm{F} 7>\mathrm{F} 5>\mathrm{F} 8$. The biggest impact in selecting the route and type of transportation for carriage of containers is that of the economic criteria $(\mathrm{F} 2=28 \%)$, the duration of transportation $(\mathrm{F} 4=17 \%)$, additional transportation fare $(\mathrm{F} 3=14 \%)$ and carbon dioxide emissions $(\mathrm{F} 1=11 \%)$.

Figures 4-7 present the cause and effect diagram for the criteria according to the results given in Table 8 .

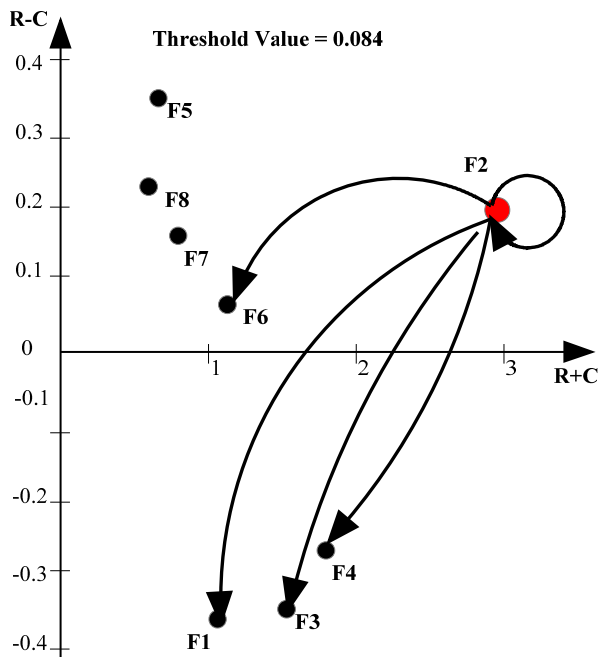

Fig. 4. Cause and effect diagram for criterion F2.

The relative importance of each criterion is presented by the values of $(\mathrm{P}+\mathrm{R})$. This impact is the same as the values of the criteria. Criteria F1, F3 and F4 are in the effect group. The values of (P-R) for these criteria are negative. Criteria F2, F5, F6, F7 and F8 are in the cause group. The values of (P-R) for these criteria are positive.
According to the results criterion F2 influenced criteria F1, F2, F3, F4 and F6; criterion F3 influenced criteria F2 and F4; criterion F4 influenced F1, F2, F3 and F7; criterion F5 influenced F2, F3 and F4; criterion F6 influenced criteria F2 and F4; criterion F7 influenced F2 and F4; criterion F8 influenced criterion F2.

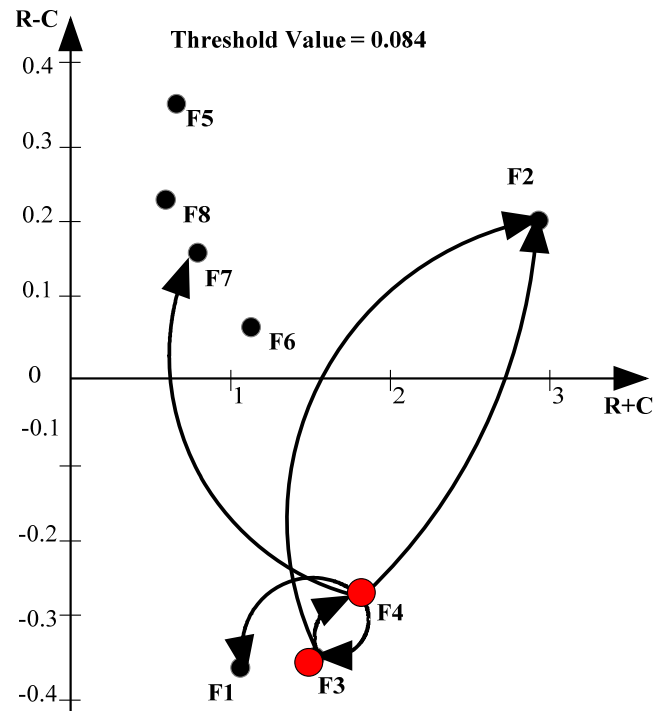

Fig. 5. The cause and effect diagram for criterion F3 and F4.

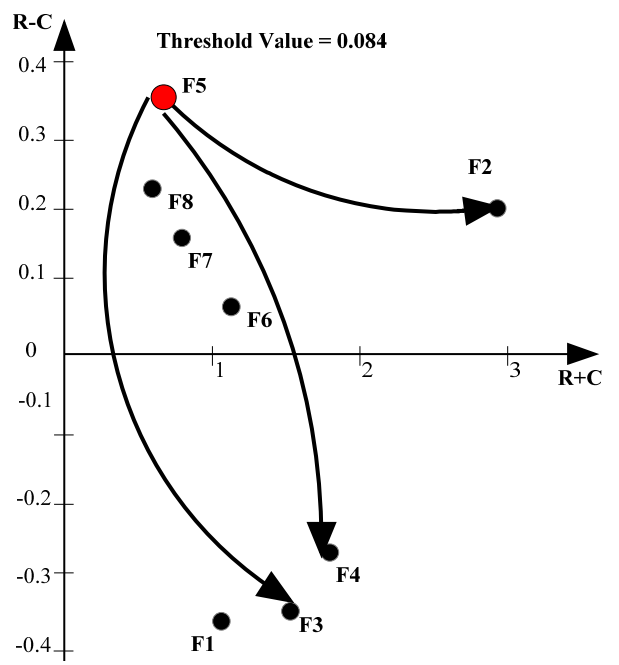

Fig. 6. Cause and effect diagram for criterion F5.

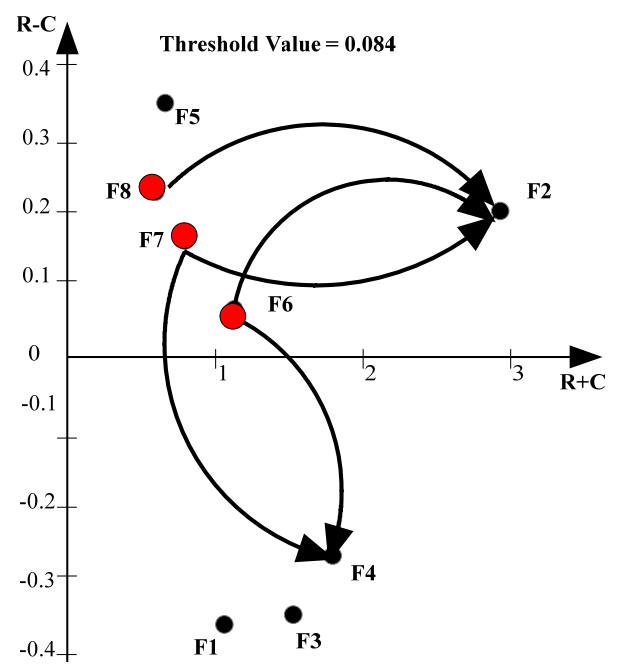

Fig.7. Cause and effect diagram for criterion F6, F7 and F8. 
Table 10 and Figure 8 present a comparison of criteria weights given by using the different methods and also the average value according to formula (7). The results show that the average absolute error between the values obtained using the Shannon Entropy method and the average values is $3 \%$; the average absolute error between the values obtained using the DEMATEL method and the average values is $1 \%$, and the average absolute error between the values obtained using the AHP method and the average values is $2 \%$.

Table 10. Comparison of the weights of the criteria.

\begin{tabular}{|c|c|c|c|c|c|c|c|c|}
\hline Criteria & F1 & F2 & F3 & F4 & F5 & F6 & F7 & F8 \\
\hline $\begin{array}{c}\text { SHANNON } \\
\text { ENTROPY }\end{array}$ & 0,20 & 0,16 & 0,09 & 0,20 & 0,09 & 0,09 & 0,09 & 0,09 \\
\hline DEMATEL & 0,11 & 0,28 & 0,14 & 0,17 & 0,06 & 0,10 & 0,08 & 0,06 \\
\hline AHP & 0,10 & 0,32 & 0,11 & 0,14 & 0,06 & 0,11 & 0,08 & 0,08 \\
\hline AVERAGE & 0,14 & 0,25 & 0,11 & 0,17 & 0,07 & 0,10 & 0,08 & 0,08 \\
\hline
\end{tabular}

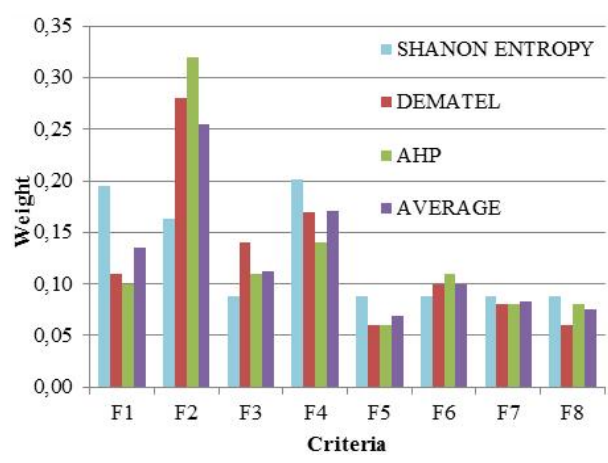

Fig. 8. Weights of the criteria.

\subsection{Ranking the alternatives by using Compromise programming}

The study examines two values of parameter $p(p=1$, and $p=2$ ). For both types of transport the charges for the use of transport infrastructure are different. The charges for using road infrastructure in Bulgaria are lower than those in the European Union, and also they are lower as compared to the charges for railway infrastructure. In many European countries, tolls have also been introduced [26]. The government policy provides for heavy goods vehicles to be covered by a toll system. The price will be determined by several components - vehicle category, toll distance, road characteristic. Two variants have been studied to evaluate the impact of infrastructure charges in choosing transport technology. Variant 1 includes values of infrastructure charges in the current situation. Usage of weekly vignette 2 times a week it has been studied. Variant 2 is with toll charges. In the research have been used the value of toll charges $0,2 \mathrm{BGN} / \mathrm{km}$, as at the time of the study is not known tariff tolls. For comparison with Poland tolls charges for vehicles with maximum permissible gross weight over 12 tons and Euro 5 emission classes is 0,27 euro/ $\mathrm{km},[26]$.

Tables 11 and 12 present the results of optimization by using the Compromise programming method with parameter $p=1$. Tables 13 and 14 show the results of optimization by Compromise programming method with parameter $p=2$.
The results show that for parameter value $p=1$, for four weights set (AHP, Shannon entropy, Equal weights and Average weights) the best technology is carriage by container block trains Sofia-Karlovo-Varna (alternative A2). According to the DEAMATEL method the best technology is carriage is by road trains via - Sofia-Veliko Tarnovo-Varna (alternative A3) route. The results for the variant with toll charges shows that the best technology is carriage of containers with block trains Sofia-KarlovoVarna (alternative A2).

Table 11. Compromise programming $(p=1)$, Vignette charges.

\begin{tabular}{|c|c|c|c|c|c|c|c|c|c|c|}
\hline Set & \multicolumn{2}{|l|}{1} & \multicolumn{2}{|l|}{2} & \multicolumn{2}{|l|}{3} & \multicolumn{2}{|l|}{4} & \multicolumn{2}{|l|}{5} \\
\hline$A j$ & $L j$ & $r$ & $L j$ & $r$ & $L j$ & $r$ & $L j$ & $r$ & $L j$ & $r$ \\
\hline A1 & 0,42 & 3 & 0,44 & 3 & 0,39 & 3 & 0,4 & 2 & 0,41 & 3 \\
\hline A2 & 0,34 & 1 & 0,34 & 2 & 0,28 & 1 & 0,35 & 1 & 0,31 & 1 \\
\hline $\mathrm{A} 3$ & 0,4 & 2 & 0,32 & 1 & 0,33 & 2 & 0,46 & 3 & 0,35 & 2 \\
\hline A4 & 0,71 & 5 & 0,71 & 5 & 0,75 & 5 & 0,68 & 5 & 0,72 & 5 \\
\hline A5 & 0,62 & 4 & 0,48 & 4 & 0,48 & 4 & 0,6 & 4 & 0,53 & 4 \\
\hline & & & $\begin{array}{l}\text { annon } \\
\text { - Equa } \\
r-1\end{array}$ & & $\begin{array}{l}\text { py; } 2 \\
\text { hts; } \\
\text { alter }\end{array}$ & & $\begin{array}{l}\text { MAT } \\
\text { verage }\end{array}$ & & & \\
\hline
\end{tabular}

Table 12. Compromise programming $(p=1)$, Toll charges.

\begin{tabular}{|c|c|c|c|c|c|c|c|c|c|c|}
\hline Set & \multicolumn{2}{|l|}{1} & \multicolumn{2}{|l|}{2} & \multicolumn{2}{|l|}{3} & \multicolumn{2}{|l|}{4} & \multicolumn{2}{|l|}{5} \\
\hline$A j$ & $L j$ & $r$ & $L j$ & $r$ & $L j$ & $r$ & $L j$ & $r$ & $L j$ & $r$ \\
\hline A1 & 0,39 & 2 & 0,4 & 2 & 0,34 & 2 & 0,39 & 2 & 0,38 & 2 \\
\hline $\mathrm{A} 2$ & 0,33 & 1 & 0,33 & 1 & 0,27 & 1 & 0,35 & 1 & 0,31 & 1 \\
\hline A3 & 0,47 & 3 & 0,48 & 3 & 0,49 & 3 & 0,52 & 3 & 0,48 & 3 \\
\hline A4 & 0,7 & 5 & 0,71 & 5 & 0,75 & 5 & 0,68 & 5 & 0,72 & 5 \\
\hline A5 & 0,69 & 4 & 0,7 & 4 & 0,64 & 4 & 0,66 & 4 & 0,66 & 4 \\
\hline & & & $\begin{array}{l}\text { nnon } \\
\text { Equa } \\
r-1\end{array}$ & & $\begin{array}{l}\text { py; } 2 \\
\text { ghts; } 5 \\
\text { f alter }\end{array}$ & tat & MA & L; & & \\
\hline
\end{tabular}

Table 13. Compromise programming $(p=2)$, Vignette charges.

\begin{tabular}{|c|c|c|c|c|c|c|c|c|c|c|}
\hline Set & \multicolumn{2}{|l|}{1} & \multicolumn{2}{|l|}{2} & \multicolumn{2}{|l|}{3} & \multicolumn{2}{|l|}{4} & \multicolumn{2}{|l|}{5} \\
\hline$A j$ & $L j$ & $r$ & $L j$ & $r$ & $L j$ & $r$ & $L j$ & $r$ & $L j$ & $r$ \\
\hline A1 & 0,24 & 3 & 0,22 & 3 & 0,2 & 3 & 0,22 & 2 & 0,22 & 3 \\
\hline A2 & 0,2 & 2 & 0,18 & 2 & 0,16 & 2 & 0,2 & 1 & 0,18 & 2 \\
\hline A3 & 0,2 & 1 & 0,16 & 1 & 0,16 & 1 & 0,23 & 3 & 0,17 & 1 \\
\hline A4 & 0,3 & 5 & 0,34 & 5 & 0,37 & 5 & 0,28 & 5 & 0,33 & 5 \\
\hline A5 & 0,29 & 4 & 0,22 & 4 & 0,21 & 4 & 0,27 & 4 & 0,24 & 4 \\
\hline & & & $\begin{array}{l}\text { annon } \\
- \text { Equ } \\
r-1\end{array}$ & & $\begin{array}{l}y ; 2 \\
\text { shts; } \\
\text { alte }\end{array}$ & & $\begin{array}{l}\text { MA } \\
\text { erag }\end{array}$ & & & \\
\hline
\end{tabular}

Table 14. Compromise programming $(p=2)$, Toll charges.

\begin{tabular}{|c|c|c|c|c|c|c|c|c|c|c|}
\hline Set & \multicolumn{2}{|l|}{1} & \multicolumn{2}{|l|}{2} & \multicolumn{2}{|l|}{3} & \multicolumn{2}{|l|}{4} & \multicolumn{2}{|l|}{5} \\
\hline$A j$ & $L j$ & $r$ & $L j$ & $r$ & $L j$ & $r$ & $L j$ & $r$ & $L j$ & $r$ \\
\hline A1 & 0,24 & 3 & 0,23 & 3 & 0,19 & 3 & 0,19 & 2 & 0,21 & 2 \\
\hline A2 & 0,2 & 1 & 0,2 & 1 & 0,16 & 1 & 0,16 & 1 & 0,18 & 1 \\
\hline A3 & 0,22 & 2 & 0,21 & 2 & 0,23 & 2 & 0,23 & 3 & 0,22 & 3 \\
\hline A4 & 0,3 & 5 & 0,34 & 5 & 0,37 & 5 & 0,37 & 5 & 0,33 & 5 \\
\hline A5 & 0,3 & 4 & 0,26 & 4 & 0,27 & 4 & 0,27 & 4 & 0,27 & 4 \\
\hline & & & $\begin{array}{l}\text { nnon } \\
\text { Equ } \\
r-1\end{array}$ & & $\begin{array}{l}\text { py; } \\
\text { ights } \\
\text { f alte }\end{array}$ & & $\mathrm{MA}^{-}$ & & & \\
\hline
\end{tabular}

The results for the value of parameter $p=2$ show that for four weights set (AHP, Shannon entropy, Equal weights and Average weights) the best technology is carriage by road trains on the Sofia-Veliko Tarnovo- 
Varna (alternative A3) route. In the case when the toll charges are introduced the best technology is transportation with container block trains Sofia-KarlovoVarna (alternative A2) for all weights sets.

Using the equal weights gives the same results for the optimal solution.

Figures 9 and 10 present the results of ranking the alternatives according to the type of road infrastructure charges. It can be seen that the prioritization of the alternatives according to the weights sets is similar. This is due to the small percentage difference in the results obtained for weights by using the various applied methods.

It can be concluded that when the value of the parameter $p=1$ is used, no difference is reported in the optimal solution for both variants of the type of road infrastructure charges. When value $p=2$, which represents the Euclidean distance, is applied there is a difference in the optimal solution for both studied variants.

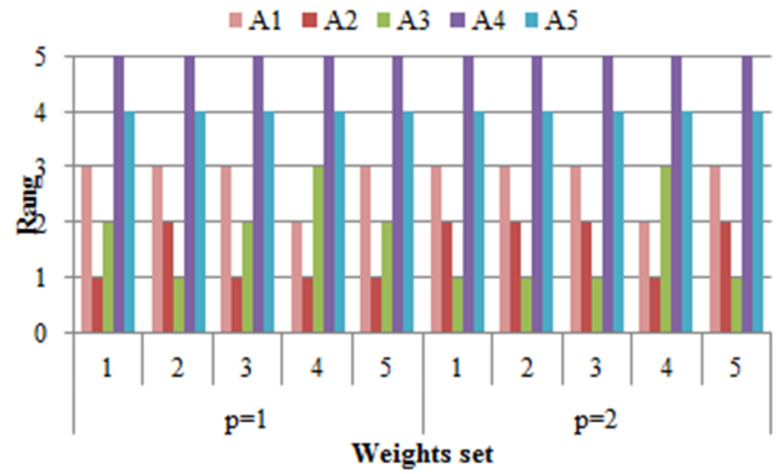

Fig. 9. Comparison of ranking of the alternatives, for the variant with vignette.

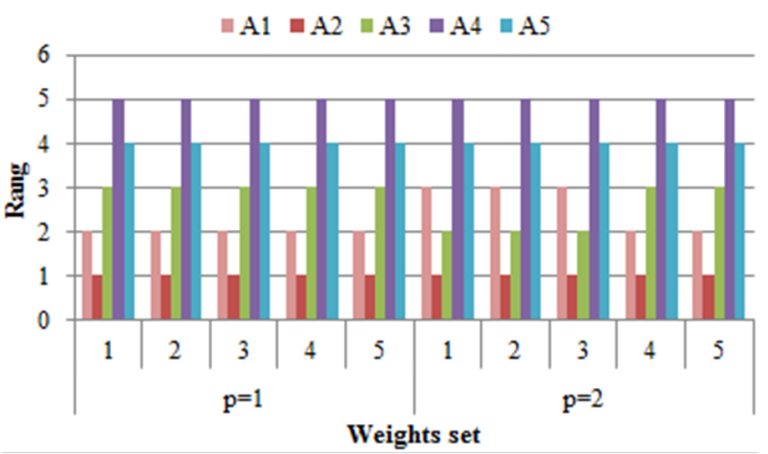

Fig. 10. Comparison of ranking of the alternatives, for the variant with toll charges.

\section{Conclusion}

- A methodology for selecting a route and a mode of transport between the initial and final points based on the Compromise programming method has been developed. The advantages of this method are the application of the type of optimization for each of the criteria, and usage of the minimum distance to the ideal solution as an optimization criterion.

- Information and expert approaches for decision-making are used to determine the criteria weights. An approach is proposed to determine the weightings of the criteria by determining the average weight for each factor from the application of two experts and one information method.

- The determination of average weights by combining expert and informative method allows us to reduce subjectivism when making a decision. This approach is recommended for use in determining the weights of the criteria.

- The effect of the Compromise programming parameter $p$ on the choice of an optimal alternative has been examined. It was found out that at the Manhattan distance $(p=1)$ the introduction of the toll charges does not affect the optimal solution. The results show that carriage with container block trains is the optimal transport technology. This is due to the fact that this distance is not the shortest to the ideal solution. At Euclidean distance $(p=2)$, the introduction of this charge affects the optimal solution. It is appropriate to use the Euclidean distance to make a decision. The results obtained at this distance are identical to those obtained in [14].

- The influence of the road infrastructure charges (vignette and toll) on the choice of route and mode of transport is studied. It has been established that the introduction of toll charges influences the choice of optimal transport technology.

\section{References}

1. D. Islam, T. Zunder, R. Jorna, Performance evaluation of an online benchmarking tool for European freight transport chains, Benchmarking: An International Journal, 20(2), 233-250 (2013)

2. B. Abramovic., I. Lovric, V. Supalo, Analysis of intermodal terminals service quality in the republic of Croatia, Promet - Traffic\&Transportation, 24(3), 253-260 (2012)

3. T. Skrucany, J. Ponicky, M. Kendra, J. Gnap, Comparison of railway and road passenger transport in energy consumption and GHG production, 12th International Scientific Conference Of Young Scientists On Sustainable, Modern and Safe Transport, TRANSCOM 2017, Procedia Engineering, 192, 806-811 (2017)

4. S. Martinov, Evaluation model of railway infrastructure potential for establishment of freight intermodal terminals, Proceedings of the 5th International Conference on Road and Rail Infrastructures - CETRA 2018, 911-916 (2018)

5. V. Pencheva, A. Asenov, D. Topchu, I. Beloev, B. Evstatiev, Organisation of the work on collecting routes in postal activity through an automated system for collection of information, Transport problems, 12(3), 147-157 (2017)

6. A. Kengpol, W. Meethom, M. Tuominen. The development of a decision support system in multimodal transportation routing within Greater Mekong sub-region countries, International Journal of Production Economics 140(2), 691-701 (2012) 
7. W. Sattayaprasert, S. Hanaoka, P. Taneerananon, R. Pradhananga, Creating a risk-based network for hazmat logistics by route prioritization with AHP: Case Study: Gasoline Logistics in Rayong, IATSS Research, 32(1), 74-87 (2008)

8. V. Podvezko, H. Sivilevicius, The use of AHP and rank correlation methods for determining the significance of the interaction between the elements of a transport system having a strong influence on traffic safety, Transport, 28(4), 389 (2013)

9. H. Sivilevicius, Modelling the interaction of transport system elements, Transport, 26(1), 20 (2011)

10. S. Stoilova, L. Kunchev, Study of criteria for evaluation of transportation with intermodal transport, Proceedings of 16th International Scientific Conference Engineering for Rural Development, Jelgava, Latvia, 349-357 (May 24-26, 2017)

11. C. Chen, Developing Taiwan into the tourist transport center of East Asia, Tourism Economics, 18(6), 1401-1411 (2012)

12. S. Gandhia, S. Mangla, P. Kumar, D. Kumar, Evaluating factors in implementation of successful green supply chain, International strategic management review, 3, 96-109 (2015)

13. S. Stoilova, L. Kunchev, Methodology for optimal transportation using a three-phase model, C. R. Acad. Bulg. Sci., 69(7), 903-908 (2016)

14. S. Stoilova, Evaluation efficiency of intermodal transport Using multi-criteria analysis, Engineering for rural development, Jelgava, 2030-2039 (May 23-25, 2018)

15. R. Li, Y. Leung, Multi-objective route planning for dangerous goods using compromise programming. J. Geogr. Syst., 13, 249-271 (2011)

16. Q. Ma, H. Song, W. Zhu. Low-carbon airline fleet assignment: A compromise approach, Journal of Air Transport Management, 68, 86-102 (2018)

17. J. Shiau, F. Wu, Compromise programming methodology for determining instream flow under multiobjective water allocation criteria, Journal of the American water resources association JAWRA, Paper No. 05013, April 2007, 1179-1191 (2007)

18. F. Andre, M. Cardenete, C. Romero, Using compromise programming for macroeconomic policymaking in a general equilibrium framework: theory and application to the Spanish economy, Journal of the Operational Research Society, 59, 875-883 (2008)

19. B. Poff, D. Tecle, G. Neary, B. Geils, Compromiise programming in forest management, Journal of the Arizona-Nevada academy of science, 42(1), 44-60 (2010)

20. R. Srinivasa, D. Kumar, Multicriterion analisis in engineering and management, 266 (PHL Learning Private Limited, Delhi, 2014)

21. A. Haddadha, A. Namazian, S. Yakhchali, Project selection problem by combination of Shannon Entropy and MCDM techniques, International
Conference on Literature, History, Humanities and Social Sciences (LHHSS-17), Dubai, 32-35 (Jan. 1-2, 2017)

22. R. Mavi, M. Goh, N. Mavi, Supplier selection with Shannon Entropy and Fuzzy TOPSIS in the context of supply chain risk management, Procedia-Social and Behavioral Sciences, 235, 216-225 (2016)

23. T. Saaty, Fundamentals of Decision Making and Priority Theory with the Analytic Hierarchy Process (RWS Publications, 2000)

24. D. Vujanovic, V. Momcilovic, N. Bojovic, V. Papic, Evaluation of vehicle fleet maintenance management indicators by application of DEMATEL and ANP, Expert Systems with Applications, 39, 10552-10563 (2012)

25. S. Khanam, J. Siddiqui, F. Talib. A DEMATEL approach for prioritizing the TQM enablers and IT resources in the Indian ICT industry, International Journal of Applied Management Sciences and Engineering, 3(1), 11-26 (2016)

26. P. Lewandowski, User charges for road infrastructure in certain European Union member states, Scientific Journals of the Maritime University of Szczecin, 48(120), 138-145 (2016) 